\title{
Fire drives functional thresholds on the savanna-forest transition
}

\author{
Vinícius de L. Dantas, ${ }^{1}$ Marco A. Batalha, ${ }^{1}$ and Juli G. Pausas ${ }^{2,3}$ \\ ${ }^{1}$ Universidade Federal de São Carlos, Department of Botany, P.O. Box 676, 13565905, São Carlos, SP, Brazil \\ ${ }^{2}$ Centro de Investigaciones sobre Desertificación - Consejo Superior de Investigaciones Cientificas, Carretera Naquera Km. 4.5
}

(Instituto Valenciano de Investigaciones Agrárias), 46113 Montcada, Valencia, Spain

\begin{abstract}
In tropical landscapes, vegetation patches with contrasting tree densities are distributed as mosaics. However, the locations of patches and densities of trees within them cannot be predicted by climate models alone. It has been proposed that plant-fire feedbacks drive functional thresholds at a landscape scale, thereby maintaining open (savanna) and closed (forest) communities as two distinct stable states. However, there is little rigorous field evidence for this threshold model. Here we aim to provide support for such a model from a field perspective and to analyze the functional and phylogenetic consequences of fire in a Brazilian savanna landscape (Cerrado). We hypothesize that, in tropical landscapes, savanna and forest are two stable states maintained by plant-fire feedbacks. If so, their functional and diversity attributes should change abruptly along a community closure gradient. We set 98 plots along a gradient from open savanna to closed forest in the Brazilian Cerrado and tested for a threshold pattern in nine functional traits, five soil features, and seven diversity indicators. We then tested whether the threshold pattern was associated with different fire regimes. Most community attributes presented a threshold pattern on the savanna-forest transition with coinciding breakpoints. The thresholds separated two community states: (1) open environments with low-diversity communities growing in poor soils and dominated by plants that are highly resistant to high-intensity fires; and (2) closed environments with highly diverse plant communities growing in more fertile soils and dominated by shade-tolerant species that efficiently prevent light from reaching the understory. In addition, each state was associated with contrasting fire regimes. Our results are consistent with the hypothesis that forests and savannas are two coexisting stable states with contrasting patterns of function and diversity that are regulated by fireplant feedbacks; our results also shed light on the mechanism driving each state. Overall, our results support the idea that fire plays an important role in regulating the distribution of savanna and forest biomes in tropical landscapes.
\end{abstract}

Key words: alternative stable states; Cerrado; community dynamics; ecological thresholds; Emas National Park, Brazil; fire regimes; phylogenetic diversity; physiognomic gradient; plant-fire feedback; plant functional traits; savanna-forest systems; tropical biomes.

\section{INTRODUCTION}

Forest and savanna are two major terrestrial biomes dominating tropical landscapes (Woodward et al. 2004). Although their occurrences at a global scale may be predicted by climate-based models, at regional to local scales patches of contrasting tree densities may occur within the same climatic conditions (Hoffmann et al. 2005, Bond 2008, Hirota et al. 2011, Ratnan et al. 2011, Staver et al. 2011, Murphy and Bowman 2012; see Plate 1). Consequently, more complex models have been proposed to explain the differences between climatebased predictions and the actual vegetation cover in tropical landscapes (Bond et al. 2005, Archibald et al. 2009, Pueyo et al. 2010, Lehmann et al. 2011, Staver and Levin 2012). There is an emerging consensus that fire

Manuscript received 21 September 2012; revised 16 April 2013; accepted 25 April 2013. Corresponding Editor: B. D. Inouye.

${ }^{3}$ Corresponding author. E-mail: juli.g.pausas@uv.es plays a fundamental role in these systems and that its relationship with vegetation dynamics is more complex than what a simple correlative model would predict (Bond and Keeley 2005, Staver et al. 2011, Murphy and Bowman 2012).

A model based on alternative stable state theory and tree growth-fire interaction (the "tree growth-fire interaction" model) has been recently proposed to explain the dynamics of savanna-forest systems (Hoffmann et al. 2012a, Murphy and Bowman 2012). Such a model was built upon the assumption that savanna and forest are two alternative stable states with distinct structures and functions that are maintained by positive plant-fire stabilizing feedbacks. The transition from savanna to forest would be dependent on the crossing of two ecological thresholds: (1) the fire-resistance threshold, i.e., the stage at which an individual tree achieves a critical bark thickness and becomes fire resistant, surpassing the fire-vulnerable juvenile stage (Hoffmann et al. 2009); and (2) the fire-suppression threshold, i.e., 
the stage at which a woodland achieves sufficient canopy closure to dramatically reduce the flammability of the system (for example, decreased light and $\mathrm{C}_{4}$ grass density and increased moisture [Hoffmann et al. 2012a]). Because species common in forest environments need more time to achieve critical bark thickness than species typical of savanna, the crossing of these thresholds would be dependent upon sufficient fire intervals (Hoffmann et al. 2012a). In landscapes where fire frequency is high, the occurrence of forest is predicted to be associated with plant growth enhancers (for example, high water or nutrient availability [Hoffmann et al. 2009, Murphy and Bowman 2012]). Although this idea is straightforward, most of the evidence for stable states in forest-savanna systems comes from indirect inferences and theoretical models (Hennenberg et al. 2006, Hoffmann et al. 2012a, Staver and Levin 2012). Because fire inhibition may be achieved at tree densities much lower than those observed in forests (Trauernicht et al. 2012), finding field evidence of these critical switching points and their consequences at the community scale would provide a more mechanistic understanding of the processes driving stable states in the tropics.

Within this framework we aim to find evidence of functional and diversity shifts consistent with two vegetation states in the Brazilian Cerrado domain, a fire-prone mosaic of savannas and forests with variable structures (Oliveira-Filho and Ratter 2002, Hoffmann et al. 2005). In this system, annual rainfall and dry season soil water availability have lower predictive power for plant physiognomies than in Australian and African savanna-forest systems (Murphy and Bowman 2012), and except for the driest sites, all levels of tree cover may occur within the same climatic conditions (Goodland and Pollard 1973, Oliveira-Filho and Ratter 2002, Hoffmann et al. 2005). Although early studies attributed the physiognomic gradient of the Cerrado to a gradient of fertility (Goodland and Polard 1973), increasing evidence suggests that soil fertility and texture alone are weak predictors of tree density (Lehmann et al. 2011, Staver et al. 2011, Hoffmann et al. 2012a) because: (1) savanna and forests have been found to be associated with a diversity of edaphic conditions (Haridasan 1992, Hoffmann et al. 2012a); (2) forest species are able to colonize and grow in these savannas in the absence of fire (Hoffmann and Franco 2003, Hoffmann et al. 2009); and (3) there is sufficient nutrient stock in the soils of open Cerrado physiognomies to support a forest biomass (Bond 2010). Forests within Cerrado landscapes tend to experience more fires than forests in other savanna-forest systems (Murphy and Bowman 2012), but the fire frequency is much lower than in open Cerrado physiognomies (Hoffmann et al. 2009, 2012a). Because Cerrado landscapes include patches with significant variability in tree densities, they offer an excellent opportunity to study functional changes and threshold effects along this community closure gradient.
We hypothesized that in Cerrado landscapes, despite the existence of a gradient of community structure (from open savannas to closed forests), there are two welldefined stable states of community function, each associated with contrasting levels of community closure and maintained by different fire regimes. Consequently, we predicted the existence of an abrupt shift in community parameters along a community closure gradient reflecting distinct vegetation states, particularly in the community parameters related to fire-plant feedbacks. Given that open communities are more flammable and that fire opens up the communities (Gambiza et al. 2000, Hennenberg et al. 2006, Higgins et al. 2007), we expected fire feedbacks to enhance not only the compositional and phylogenetic differences between the alternative states but also the differences in fire escape strategies in a fire-prone landscape. Specifically, we expected fire-plant feedbacks to segregate open communities dominated by fire-resistant species with early investments in bark thickness and high vegetative recovery rates from communities dominated by firesensitive species, which protect themselves from fire by efficiently closing the canopy and reducing the flammability of the system (Hoffmann et al. 2012b). In landscapes where fire is frequent, forests are predicted to be restricted to high-resource soils, which decreases the time needed to accumulate fire-protective barks and to achieve canopy closure and thus fire inhibition (Hoffmann et al. 2009). Thus we expected soil fertility to change abruptly along the community closure gradient. Finally, the consequences of different ecological settings (light and nutrient availability, fire regime) between open and closed communities should also have implications for species assembly and community diversity. To evaluate these predictions, we sampled plant functional traits, soil nutrients, and plant diversity attributes along a savanna-forest gradient (that is, a community closure gradient) in a Cerrado reserve (Emas National Park, Brazil) and tested for the existence of consistent thresholds separating communities with contrasting fire regimes. Our results will be consistent with two vegetation states maintained by plant-fire stabilizing feedbacks if (1) community attributes (particularly the ones discussed here) show a significant breakpoint along the community closure gradient; (2) the threshold model defined by this breakpoint explains significantly more variability than a linear model; and (3) there are different fire regimes on the different sides of the threshold.

Materials And Methods

\section{Study site}

Emas National Park (ENP) is a 132 000-ha World Heritage site containing flora, fauna, and key habitats that characterize the Cerrado. It is located in the Brazilian Central Plateau, in the southwest of the state of Goiás $\left(17^{\circ} 49^{\prime}-18^{\circ} 28^{\prime} \mathrm{S}\right.$ and $\left.52^{\circ} 39^{\prime}-53^{\circ} 10^{\prime} \mathrm{W}\right)$. All of the Neotropical savanna physiognomies can be found 
within the park, but open Cerrado physiognomies predominate, covering $\sim 68 \%$ of the area; dense savannas and forests cover $\sim 25 \%$ and $1.2 \%$ of the area, respectively (Ramos-Neto and Pivello 2000; see Appendix A). The climate is tropical humid (Aw, following Köppen 1931), with two well-defined seasons: a dry season (from May to September) and a warmer rainy season (from October to April). The annual rainfall varies between 1200 and $2000 \mathrm{~mm}$, concentrated mainly from October to March, and mean annual temperature is $24.6^{\circ} \mathrm{C}$ (Ramos-Neto and Pivello 2000). The soils are mainly dystrophic Oxisols. Until 1984, the park was exploited by cattle ranchers, and fire was used to generate fodder (Ramos-Neto and Pivello 2000). After a large fire in 1994 that burned most of the park, the fire management policy of the reserve was changed: natural fires are now allowed in the park, and a network of annually burned firebreaks limits the spread of fires (Ramos-Neto and Pivello 2000). Hence, large fires burning throughout the park became less frequent. During the sampling period, the ENP was a mosaic of patches with differing fire histories.

\section{Sampling}

Using a map of time since last fire and a GIS, we set $1005 \times 5 \mathrm{~m}$ plots stratified by fire age and located near small roads. For practical and legal reasons, plots that fell in an inaccessible region of the park were discarded. We also discarded plots with fewer than three woody individuals (stem diameter at the ground level $\geq 3 \mathrm{~cm}$ ) and those with fewer than two species. Because the areas that were unburned for $>15 \mathrm{yr}$ were all relatively small forest fragments, most of which were inaccessible, we distributed 20 plots systematically in two accessible forest fragments. The final analysis included 98 plots with different fire ages (from $1 \mathrm{yr}$ to $>32 \mathrm{yr}$ ) and different vegetation structures. Forest plots corresponded to typical semideciduous forests of the region and were set every $50 \mathrm{~m}$ along the trail that crosses each of the forest fragments and at $20 \mathrm{~m}$ from the trail. The ENP is mostly flat, and there were no strong topographic differences among the sampled plots. During the rainy seasons of 2009-2010 and 2010-2011 we sampled in each plot all woody individuals with stem diameter at the ground level $\geq 3 \mathrm{~cm}$ and identified them to species. For each individual we measured plant height, stem diameter, bark thickness, and leaf toughness, and collected leaf, wood, and soil samples for further analyses (Appendix B: Field sampling). In the laboratory, we calculated the height-to-diameter ratio and bark thickness-to-diameter ratio and measured the specific leaf area, leaf nitrogen, phosphorus and potassium content, and wood density (Appendix B: Plant functional traits). These functional traits are related to fire resistance (bark thickness-to-diameter ratio; Lawes et al. 2012), vegetative recovery ratios (wood density; Curran et al. 2008), topkill (height-todiameter ratio; Dantas et al. 2013), shade tolerance (specific leaf area; Westoby et al. 2002), and nutrient use (specific leaf area, leaf toughness, and leaf nutrient contents; Westoby et al. 2002, Craine 2009). Traits were measured in all individual plants because intraspecific variability is an important component of trait variability that influences species assembly (Jung et al. 2010, Viole et al. 2012, Dantas et al. 2013). Composite soil samples from each plot were sent to the Soil Science Laboratory at the University of São Paulo, where soil organic matter content $(\mathrm{OM})$ and the concentration of available phosphorus $(\mathrm{P})$, total nitrogen $(\mathrm{N})$, cations $(\mathrm{Ca}, \mathrm{Mg}$, $\mathrm{K}$ ), and aluminum ( $\mathrm{Al})$ were determined (Appendix $\mathrm{B}$ : Soil data).

\section{Fire history}

We used annual satellite images from 1979-2010 to determine fire years in each plot. Images from 19791983 were obtained from the satellites Landsat 1, 2, and 3 (Multispectral Scanner System; 80-m resolution), whereas images from 1984-2010 were obtained from the satellites Landsat 5 and 7 (Thematic Mapper and Enhanced Thematic Mapper; 30-m resolution). The mean fire interval for each plot was determined as the inverse of fire frequency in the plot. We assigned the maximum fire interval $(32 \mathrm{yr}$ ) for plots that had not burned within the period we examined.

\section{Community closure index}

To test whether community parameters displayed a threshold relationship along the savanna-to-forest gradient, we calculated a community closure index (CCI) as the sum of the woody volume of all plants in the plot, standardized to vary from 0 to 1 . We computed the woody volume of each individual tree, assuming a cone shape (i.e., basal area $\times$ height $/ 3$ ). The index was used as an indicator of the light environment, from open communities (CCI close to 0) to closed communities (CCI close to 1). We did not consider tree cover because of the low resolution at the extremes of the gradient. Basal area was also discarded because plots with the same basal area (especially at intermediate basal area values) may vary substantially in structure, depending on the height of the plants. Our index is expected to be more sensitive to fine-scale variability in light incidence than tree cover or basal area and is therefore more appropriate for testing our hypothesis (see Appendix C). Indeed, evidence points out that woody volume is better in distinguishing Cerrado physiognomies than is basal area (Batalha et al. 2001). Moreover, combined plant height and stem diameters are good predictors of canopy leaf biomass in the Cerrado (Delitti et al. 2006), and there is evidence that wood volume is also a good predictor (Salis et al. 2006). Thus we expected CCI to reflect the changes in structure and the light environment along the transition from open savanna to forest. The CCI enabled us to order the plots according to community closure and test for threshold patterns in community parameters along the gradient. 
TABLE 1. Summary of the detection of thresholds in different community attributes (soil properties, plant traits, and diversity indices) along the community closure gradient in the Brazilian Cerrado.

\begin{tabular}{|c|c|c|c|c|c|c|c|c|c|}
\hline \multirow[b]{2}{*}{ Community attribute } & \multicolumn{2}{|c|}{$\sup (F)$ test } & \multicolumn{3}{|c|}{ LR } & \multicolumn{2}{|c|}{ PR } & \multirow{2}{*}{$\begin{array}{c}\text { ANOVA } \\
\text { (LR vs. PR) } \\
F_{2,94}\end{array}$} & \multirow[b]{2}{*}{$\Delta \mathrm{AIC}_{\mathrm{c}}$} \\
\hline & $F_{1,96}$ & Breakpoint & Slope & $R^{2}$ & $P$ & $R^{2}$ & $P$ & & \\
\hline Soil organic matter & $51.42 * * *$ & 0.57 & 6.32 & 0.17 & $<0.001$ & 0.30 & $<0.001$ & $9.25 * * *$ & 13.20 \\
\hline Soil nitrogen & $101.62 * * *$ & 0.57 & 448.15 & 0.32 & $<0.001$ & 0.46 & $<0.001$ & $13.18 * * *$ & 19.82 \\
\hline Soil phosphorus & $63.02 * * *$ & 0.57 & 1.90 & 0.24 & $<0.001$ & 0.38 & $<0.001$ & $10.13 * * *$ & 14.73 \\
\hline Soil sum of bases & $36.72 * * *$ & 0.58 & 4.89 & 0.12 & $<0.001$ & 0.35 & $<0.001$ & $15.98 * * *$ & 24.03 \\
\hline Soil aluminum saturation & $74.83 * * *$ & 0.58 & -5.11 & 0.25 & $<0.001$ & 0.45 & $<0.001$ & $17.67 * * *$ & 27.05 \\
\hline Height to diameter ratio & $172.54 * * *$ & 0.59 & 98.79 & 0.52 & $<0.001$ & 0.64 & $<0.001$ & $15.03 * * *$ & 52.79 \\
\hline Bark thickness to diameter ratio & $61.08 * * *$ & 0.56 & -0.02 & 0.30 & $<0.001$ & 0.39 & $<0.001$ & $11.23^{* * *}$ & 9.04 \\
\hline Wood density & $84.56^{* * *}$ & 0.57 & 0.04 & 0.43 & $<0.001$ & 0.49 & $<0.001$ & $6.23 * *$ & 7.79 \\
\hline Leaf toughness & $24.94 * * *$ & 0.58 & -0.10 & 0.15 & $<0.001$ & 0.20 & $<0.001$ & $3.63 *$ & 2.89 \\
\hline Specific leaf area & $181.47 * * *$ & 0.57 & 1.45 & 0.50 & $<0.001$ & 0.66 & $<0.001$ & $21.44 * * *$ & 32.43 \\
\hline Leaf nitrogen & $12.43^{* *}$ & 0.43 & 0.04 & 0.12 & $<0.001$ & 0.13 & 0.001 & $0.79^{\text {ns }}$ & -3.36 \\
\hline Leaf phosphorus & $11.24 *$ & 0.57 & -0.03 & 0.05 & 0.032 & 0.08 & 0.004 & $0.18^{\mathrm{ns}}$ & -0.81 \\
\hline Leaf potassium & $4.85^{\mathrm{ns}}$ & & -0.04 & 0.03 & 0.078 & & & & \\
\hline Mean phylogenetic distance & $39.57 * * *$ & 0.56 & 12.01 & 0.26 & $<0.001$ & 0.30 & $<0.001$ & $2.38^{\mathrm{ns}}$ & 0.46 \\
\hline Phylogenetic community distance $\dagger$ & $75.31 * * *$ & 0.57 & 11.44 & 0.30 & $<0.001$ & 0.44 & $<0.001$ & $11.84 * * *$ & 17.62 \\
\hline Jaccard's beta diversity & $64.59 * * *$ & 0.57 & 90.87 & 0.26 & $<0.001$ & 0.39 & $<0.001$ & $10.21 * * *$ & 14.86 \\
\hline Composition dissimilarity $1 \uparrow$, & $54.21 * * *$ & 0.57 & 69.07 & 0.31 & $<0.001$ & 0.37 & $<0.001$ & $4.04 *$ & 3.75 \\
\hline Composition dissimilarity $2 \uparrow, \S$ & $99.07 * * *$ & 0.59 & 39.77 & 0.39 & $<0.001$ & 0.50 & $<0.001$ & $11.21 * * *$ & 16.56 \\
\hline Shannon's diversity & $55.22 * * *$ & 0.56 & 0.18 & 0.39 & $<0.001$ & 0.42 & $<0.001$ & $2.69^{\mathrm{ns}}$ & 1.04 \\
\hline Richness & $56.07 * * *$ & 0.56 & 0.84 & 0.40 & $<0.001$ & 0.44 & $<0.001$ & $2.88^{\mathrm{ns}}$ & 1.42 \\
\hline
\end{tabular}

Notes: Structural change analysis (supremum of $F$ test, which computes $F$ statistics and then performs a Chow test), linear regression (LR), and piecewise regression (PR) are shown. The comparison between the linear and the piecewise model was performed by an ANOVA (LR vs. PR); the changes in $\mathrm{AIC}_{\mathrm{c}}$ are also shown. Thresholds are defined as significant breakpoints $[\sup (F)$ test] with a piecewise model explaining significantly more variability than the linear model.

$* P \leq 0.05 ; * * P \leq 0.01$; *** $P \leq 0.001$. Results that are not significant are denoted "ns."

$\uparrow$ Beta diversity indices were measured cumulatively along the community closure index gradient.

$\$$ Abundance-based.

$\S$ Considering presence/absence only.

\section{Numerical analyses}

We computed alpha and beta diversity for each plot along the CCI gradient, considering both traditional (nonphylogenetic) as well as phylogenetic-based indices, as described in Appendix B.

To test for threshold-type relationships (i.e., abrupt changes) among community attributes along the CCI gradient (against the null hypotheses of no pattern or a simple linear pattern), we used the following procedure for each community attribute: (1) We first tested for significant structural changes in the distribution of the community parameter along the CCI gradient by fitting an ordinary least-square model before and after every possible breakpoint in the variable distribution and computing $F$ statistics for all potential breakpoints. The breakpoint with the greatest $F$ value for each variable was tested for significance with a $\sup (F)$ test (supremum of $F$ ) for structural change (Hansen 1997). The $\sup (F)$ test is a test for structural changes that computes the $F$ statistics and subsequently performs a Chow test. (2) We then fitted a linear regression to test for linear relationships between the community parameter and CCI. (3) Finally, we fitted a piecewise regression to variables that presented significant breakpoints using the breakpoint values obtained in step 1. Piecewise regressions are models in which two or more lines are fitted to the data and joined by breakpoints representing thresholds (Toms and Lesperance 2003). We fitted a simple piecewise regression model with one breakpoint and two linear regressions fit at each side of the breakpoint value of CCI obtained in step 1. When necessary, we log-transformed the data to improve normality of the residuals. A threshold relationship between CCI and the parameter was inferred when (1) there was a significant breakpoint $(\sup (F)$ test); and (2) the piecewise model fitted significantly better and had lower AICc than the linear model. Finding a significant breakpoint but not a better fit of the piecewise model compared to the linear model would suggest that there is a functional change between the two vegetation states but that the switch is not so abrupt. We used the mean of all threshold values of CCI obtained in the structural change analysis to separate the area into two states (low and high CCI). We then compared mean fire intervals between the two states with Student's $t$ test. We carried out all the analyses in $\mathrm{R}$ version 2.11 ( $\mathrm{R}$ Development Core Team 2011) using the betapart, picante, strucchange, and vegan libraries.

\section{RESUlts}

We sampled a total of 710 individuals of 98 species in 39 taxonomic families. All of the soil variables and diversity indices and all but one of the functional traits presented a significant breakpoint $(\sup (F)$ test; Table 1$)$. Most parameters with a significant breakpoint also showed an improved fit when using the piecewise model 

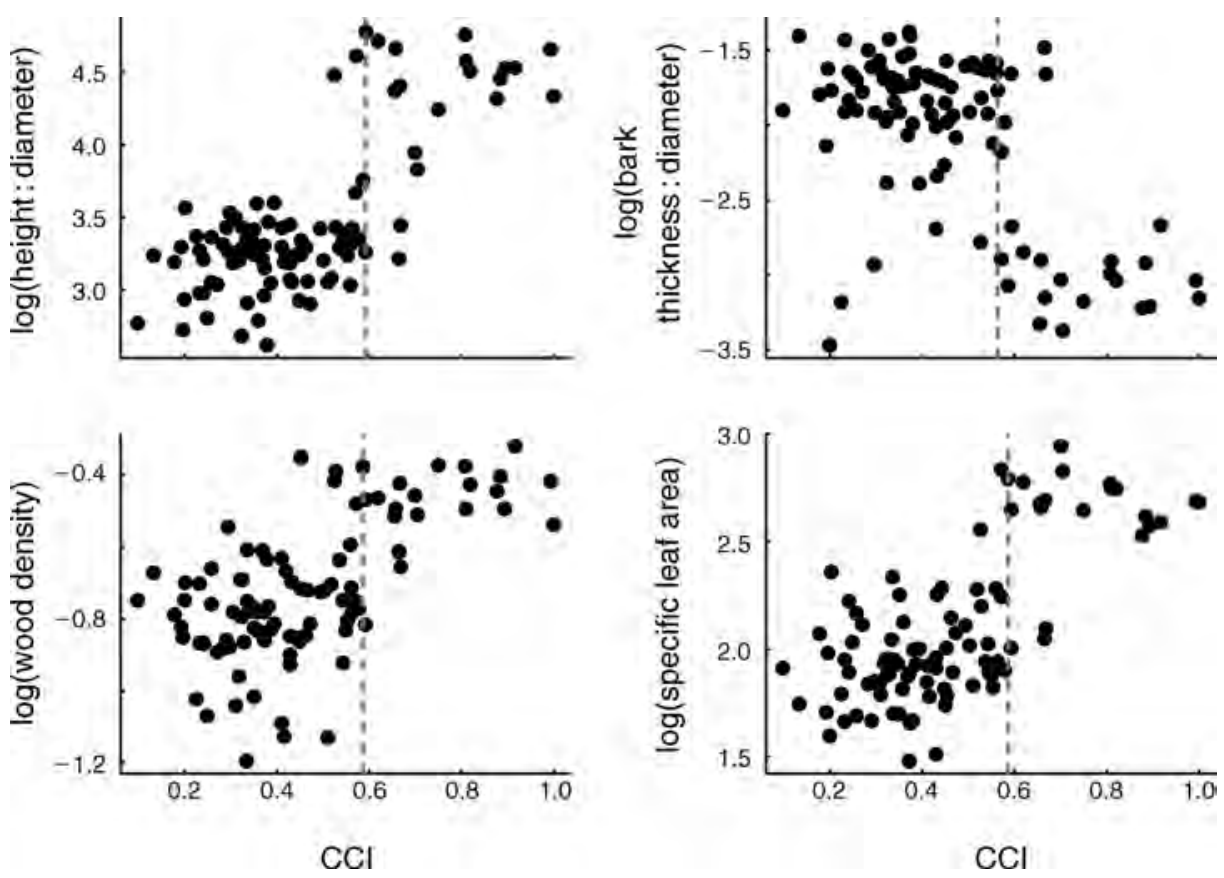

FIG. 1. Log-transformed height-to-diameter ratio, bark thickness-to-diameter ratio, wood density (originally measured as mg/ $\mathrm{mm}^{3}$ ), and specific leaf area (SLA; originally measured as $\mathrm{mm}^{2} / \mathrm{mg}$ ) along the community closure index gradient (CCI, from 0 to 1 ) as examples of the threshold-type relationships found at Emas National Park in central Brazil. Vertical gray lines represent significant breakpoints $(P<0.001$; Table 1$)$. For more examples see Appendix D.

compared to a linear model (Table 1; Fig. 1; Appendix D), suggesting that the breakpoint is rather abrupt. Soil features presented threshold patterns with breakpoints between 0.56 and 0.58 community closure index (CCI) that separated areas with low soil fertility (at low CCI) from areas with high soil fertility (at high CCI). All but three functional traits (leaf nutrient contents) presented a threshold pattern with breakpoints between 0.56 and 0.59 CCI (Table 1), although the functional change in leaf toughness was relatively small. Breakpoints separated communities dominated by plants with low heightto-diameter and high bark thickness-to-diameter ratios, low wood densities, and tougher leaves with low specific areas (at low CCI) from communities with the opposite characteristics (at high CCI). Most of the beta diversity indicators (phylogenetic and nonphylogenetic) presented a clear threshold-type distribution in relation to CCI, suggesting a compositional and phylogenetic turnover. However, alpha diversity measures (mean phylogenetic distance, Shannon diversity, and species richness) and abundance-weighted composition dissimilarity presented significant breakpoints with a nonsignificant or slightly significant increased fit by the piecewise model (Table 1), suggesting that the shifts in these parameters are not abrupt.

Considering all significant breakpoints in the $\sup (F)$ test with an improved fit by the piecewise model, the mean threshold was located at $\mathrm{CCI}=0.57 \pm 0.009$ (mean $\pm \mathrm{SD})$. This mean threshold separated two clear states with contrasting community attributes (Fig. 2,
Appendix E). The mean fire interval differed significantly before and after this mean threshold ( $t$ test; $t=$ $-9.085, P<0.001)$ with clearly longer mean fire intervals associated with plots located at the high end of the CCI gradient (Fig. 3).

\section{DisCUSSION}

Soil properties, phylogenetic and nonphylogenetic beta diversities, and most of the plant functional traits presented a threshold pattern along the community closure index (CCI) gradient with coinciding breakpoints, providing strong evidence of a functional threshold along the forest-savanna gradient. Open environments consisted of communities growing on poor soil and dominated by short species, with early investments in thick barks and low wood density and with thick and tough leaves (high toughness and low specific area). In contrast, closed communities grew in more fertile soils and included plants having the opposite functional attributes. Moreover, we found contrasting fire regimes on the two sides of the threshold, with open formations showing shorter fire intervals than closed formations and a switch from communities dominated by fire-resistant plants to communities dominated by shade-tolerant species that compensate for their lack of fire resistance by efficiently closing the canopy (i.e., reducing flammability). Overall, our results are consistent with the theoretical model of fire-plant feedbacks as main drivers of the coexistence of two stable states, savanna and forest (Hoffmann et al. 

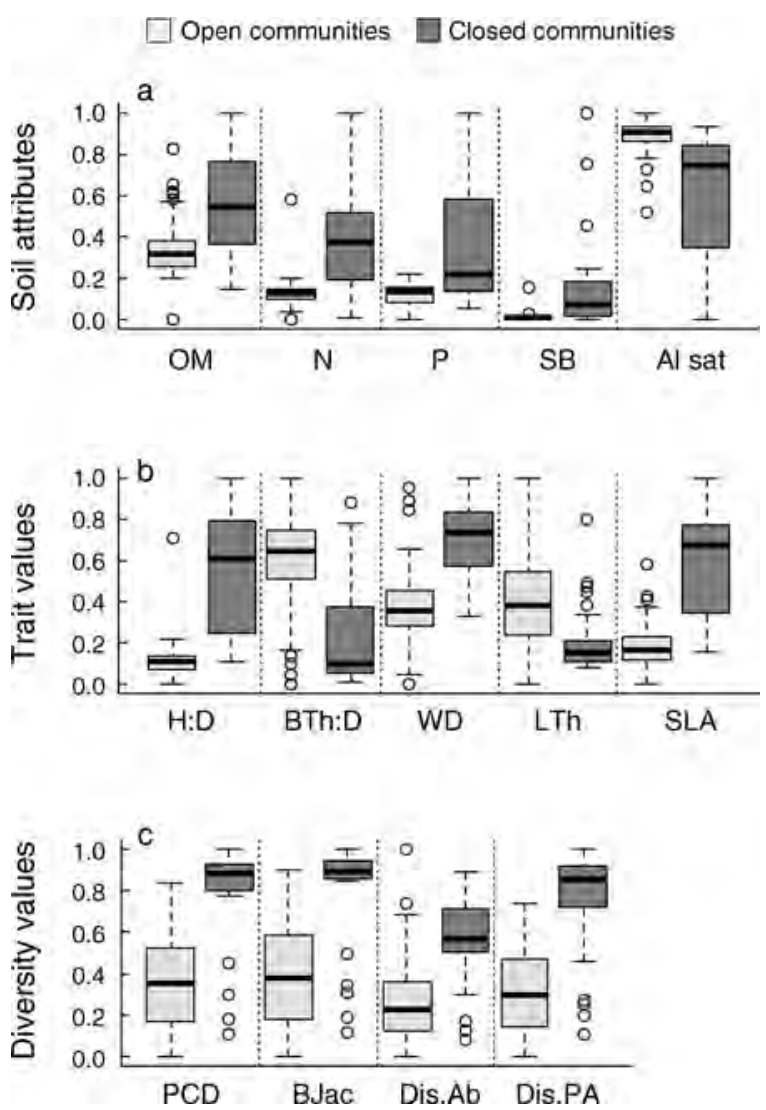

FIg. 2. Community attributes (standardized from 0 to 1 ) at each side of the mean threshold $(\mathrm{CCI}=0.57)$ along the CCI gradient (for attributes with greater variability explained by the piecewise model; Table 1). Light gray indicates open communities $(\mathrm{CCI}<0.57)$; dark gray indicates closed communities $(\mathrm{CCI} \geq 0.57)$. Open and closed communities correspond to the plots where community closure indices are smaller and greater, respectively, than the mean breakpoint obtained in Table 1 along the community closure gradient. (a) Soil: organic matter $(\mathrm{OM})$, nitrogen $(\mathrm{N})$, phosphorus $(\mathrm{P})$, sum of bases $(\mathrm{SB})$, and aluminum saturation (Al sat). (b) Traits: height-to-diameter ratio (H:D), bark thickness-to-diameter ratio (BTh:D), wood density (WD), leaf toughness (LTh), and specific leaf area (SLA). (c) Diversity indices: phylogenetic community distance (PCD), Jaccard's beta diversity (BJac), abundance-based community dissimilarity (Dis.Ab), and presence-absence-based community dissimilarity (Dis.PA). Thick bars show medians, boxes show lower and upper quartiles, whiskers show maximum and minimum values, and open circles show outliers.

2012a, Murphy and Bowman 2012). In this context, we provide the first field-based evidence for a communitylevel threshold separating two vegetation states, with distinct functional and phylogenetic characteristics and associated with different fire regimes.

The functional characteristics of plants associated with the two states support the idea that these communities are maintained by plant-fire feedbacks. In open communities, grasses are often tall, whereas trees and shrubs are small, leaving no fuel gaps between grasses and woody plants (Appendix A: Fig. Alf). Consequently, fires in open communities affect the whole plant (Appendix A: Fig. Ala). However, Cerrado plants typically have thick, often corky barks that protect the whole stem (see Appendix A: Fig Ald for an example). Depending on the fire intensity, the bark effectively protects a portion of fully scorched branches, and the plant resprouts epicormically from the protected lateral buds. This pattern results in trees with branched architectures. When combined with recurrent topkill and the need for stocking resources for resprouting, it results in slow growth in height (low height-to-diameter ratios; Higgins et al. 2007, Dantas et al. 2013) and light woods (high rates of vegetative resprout; Curran et al. 2008). This pattern differs from other savannas (e.g., many oak savannas and pine savannas) in which plants have a relatively thick stem bark and there is a clear fuel gap between the grass layer and the overstory, protecting branches and leaves from surface fires (Glitzenstein et al. 1995, Peterson and Reich 2001, Keeley et al. 2012). In contrast, open Cerrado trees with corky bark in both stem and branches are similar to some Mediterranean trees with very thick bark that resprout epicormically after crown fires (Pausas 1997, Catry et al. 2012). In closed communities, fire is inhibited because shadetolerant plants quickly occupy light gaps, preventing light-demanding $\mathrm{C}_{4}$ grasses from establishing. This effect, combined with the changes in microclimatic condition promoted by a closed canopy, drastically reduces the flammability of the system (Hoffmann et al. 2012b), allowing these fire-sensitive, shade-tolerant species that possess high wood density to support large crowns (Enquist et al. 1999, Markesteijn et al. 2011), and high photosynthetic ratios per unit leaf mass to quickly occupy open light gaps (high specific leaf area; Westoby et al. 2002). Although bark thickness is the

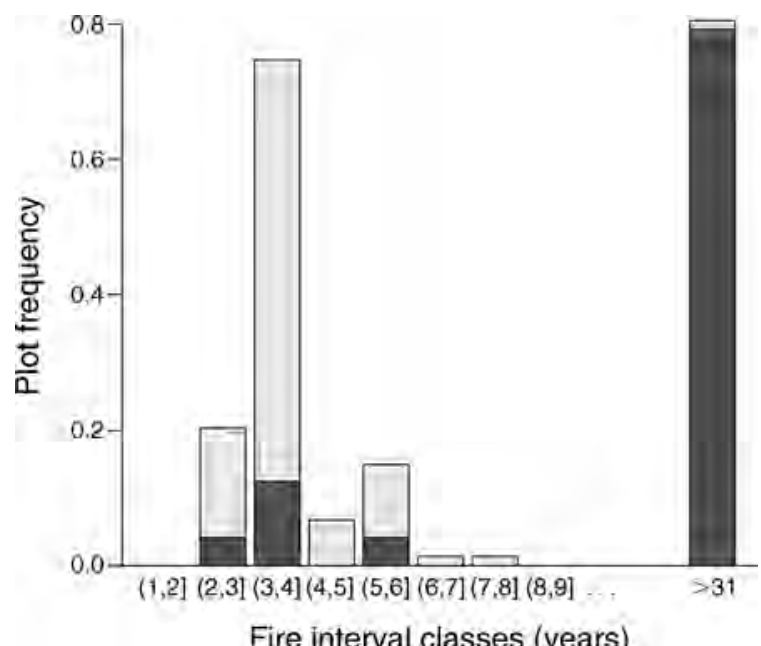

FIG. 3. Frequency distribution of plots in relation to mean fire interval (MFI; grouped into one-year interval classes) for plots with low community closure index (light gray bars; $98 \%$ of the plots have MFI $<6 \mathrm{yr}$ ) and for plots with high community closure index (dark gray bars; $79 \%$ of the plots have MFI $>30$ yr). 


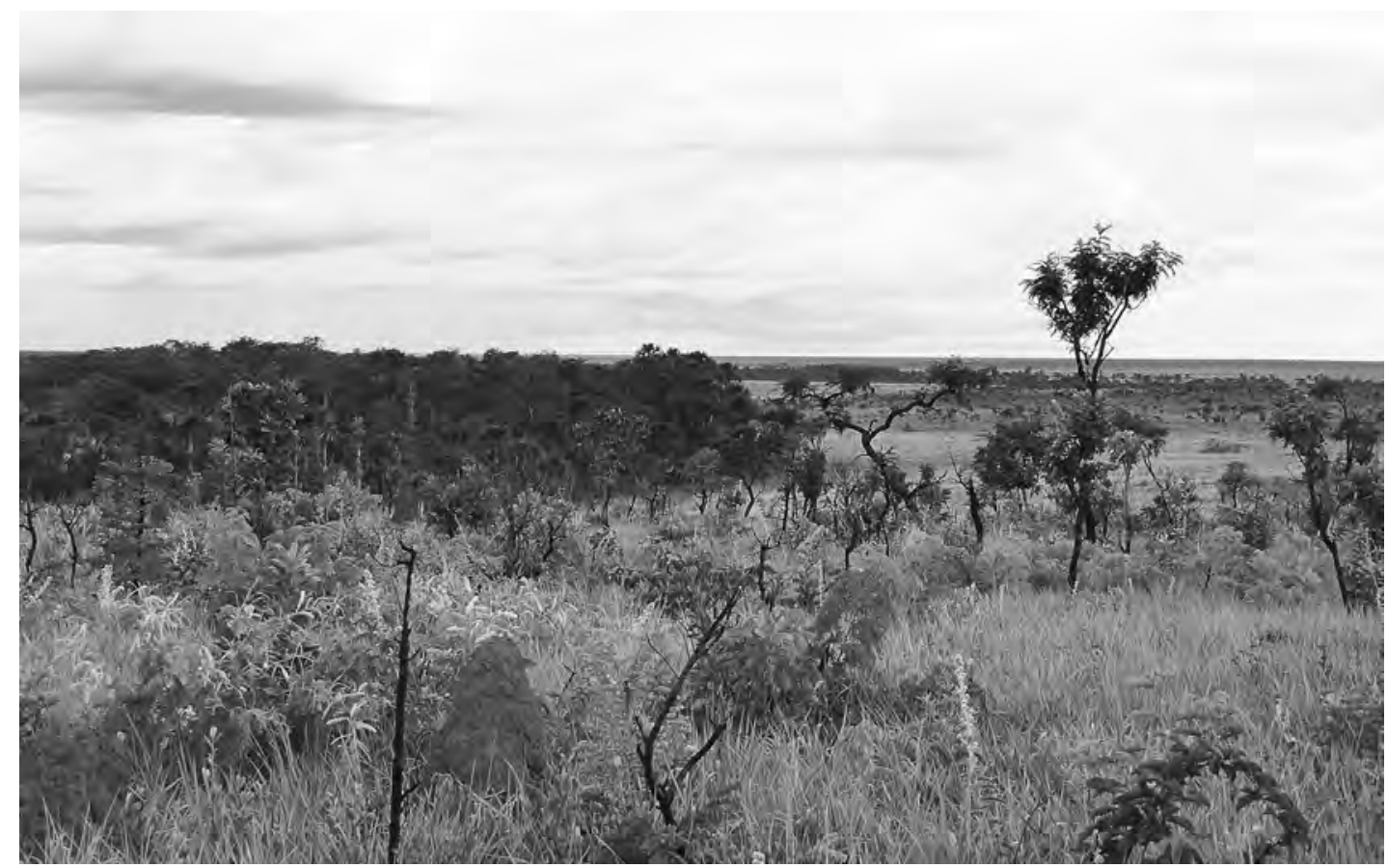

Plate 1. In tropical landscapes, vegetation patches of contrasting tree densities occur within the same climatic conditions, forming mosaics. The photograph was taken at Emas National Park (Goiás, Brazil). Photo credit: V. de L. Dantas.

most important trait preventing tree and stem mortality in Neotropical forests and savannas (Hoffmann et al. 2009, Brando et al. 2012), high wood density, large stem diameter, and high canopies are also associated with reduced levels of stem mortality in tropical savannas and forests (Archibald and Bond 2003, Brando et al. 2012). These characteristics of forest species as well as the high absolute bark thickness provided by large stems may be important to prevent low-intensity surface fires from opening the community.

High and low specific leaf areas were associated with closed and open communities, respectively. Specific leaf area is a key trait related to the leaf economic spectrum, and high specific leaf area is often associated with high photosynthetic capacity per unit leaf mass and fast leaf turnover (Westoby et al. 2002). These characteristics confer an efficient response to light patchiness (Westoby et al. 2002) and may allow forest species to quickly reach canopy closure in the absence of fire. Thus, mixed communities of shade-tolerant forest and shade-intolerant Cerrado species become unstable and rare (Hoffmann et al. 2009, Ratnam et al. 2011), leading to a threshold pattern. On the open side of the threshold, soils are nutrient poor, and recurrent fires cause frequent nutrient losses by consuming live and dead biomass (Pivello and Coutinho 1992); the need for a large carbohydrate reserve for resprouting in this system may favor plants with high nutrient-use efficiency and leaves with high investments in leaf structure and low palatability to herbivores to avoid nutrient loss (low specific leaf areas and high leaf toughness [Westoby et al. 2002, Craine 2009]).
All soil nutrients presented a clear threshold pattern, with greater fertility in the soil (high nitrogen, phosphorus, sum of bases, and organic matter, and low aluminum saturation) associated with closed communities. Nutrient stock analysis has been used to demonstrate that the size of the nutrient pool in the soil of Neotropical savannas is not a limiting factor preventing the development of a forest biomass (Bond 2010). Indeed, many forest species are able to establish and develop in nutrient-poor soils of adjacent Neotropical savannas, suggesting that the nutrient pool is not a limiting factor to forest species (Hoffmann et al. 2009). Moreover, tropical savannas and forests have been found to occur within both nutrient-rich and nutrientpoor soils (Bond 2008, 2010, Hoffmann et al. 2012a), and without sufficiently long fire intervals, forests cannot replace savannas, despite soil fertility (Hoffmann et al. 2009, 2012a, Rossatto et al. 2009). Instead, increasing evidence suggests that the effect of soil on tree growth rates and how it affects the probability of a given community achieving fire inhibition are more likely to be the pathways by which soil affects biome distribution in the tropics (Bond 2010, Hoffmann et al. 2012a, Murphy and Bowman 2012). Because the breakpoints in fire-related traits coincide with those of soil, our results are consistent with the idea of fire as the main driver of the thresholds observed here, whereas soil fertility decreases the time needed for crossing the fireinhibition threshold (Hoffmann et al. 2009, 2012a).

Flammability in the Cerrado is a function of community closure, and it shifts abruptly once a certain 
level of community closure is achieved. After this point, fire recurrence and/or intensity are predicted to be critically low (Hoffmann et al. 2012b). Our results for three decades of fire history support this prediction. The contrasting fire regimes associated with contrasting patterns in community parameters, including fire-related ones, indicate that plant-fire stabilizing feedbacks are linked to changes in fire regimes. Changes in fire regime associated with community closure were also observed in the Australian savannas, where low-intensity fires or fire inhibition was associated with closed-canopy communities, and high-intensity fires were associated with open-canopy communities (Trauernicht et al. 2012). Open communities are subject to frequent fires that often affect most of the plants, whereas in closed communities fires are rare, and when they occur are often very low-intensity surface fires (Trauernicht et al. 2012). This pattern is most likely related to the inhibition of grassy fuels, the decrease in wind speed and air temperature, and the increase in fuel moisture achieved after crossing a critical community closure threshold (Hoffmann et al. 2012b, Trauernicht et al. 2012). Although we might have missed some understory fires in closed communities on the satellite images, these fires are of low intensity, as forests tolerate them without opening large gaps that could change vegetation state. Moreover, a change from fires that fully burn the trees to understory surface fires represents an abrupt change in fire intensity consistent with a fire-inhibition threshold and with the stable state theory. Thus our data provide additional evidence that after a certain canopy closure is achieved, fires that topkill larger plants are absent for long periods, in contrast with the savannas, where the lack of a fuel gap between grasses and woody plants often results in crown fires.

Phylogenetic and nonphylogenetic beta diversities shifted along the gradient of the $\mathrm{CCI}$, reflecting the compositional and phylogenetic differences among open and closed communities. Despite the existence of congeneric forest and savanna species (Hoffmann and Franco 2003, Simon et al. 2009), abrupt changes in abiotic conditions associated with high phylo-beta diversity (i.e., high phylogenetic turnover as measured by the phylogenetic community distance index) are indications of phylogenetic conservatism of species niches and their associated traits (Graham and Fine 2008). Moreover, high beta and phylo-beta diversities are expected when there is a limited dispersal of a species from one environment to another, or when an entire clade is locally missing (Graham and Fine 2008). Given that there was not limited dispersal between savanna and forest sites (i.e., they belong to the same regional species pool), the threshold pattern in the two beta diversity indices indicates that the observed differences are ecological rather than biogeographical and emphasizes the different assembly processes between the two vegetation states (Graham and Fine 2008). Mean phylogenetic distance also presented a breakpoint in its distribution with lower values in open communities. This result is consistent with findings in mediterranean ecosystems in which high fire activity drives the cooccurrence of closely related species (Verdú and Pausas 2007). Nevertheless, the shifts were not abrupt compared with other community attributes.

In summary, we provided field-based evidence for the existence of functional and diversity thresholds that are consistent with the hypothesis that savanna and forest are two stable states. Plant height-to-diameter and bark thickness-to-diameter ratios, woody density, and specific leaf area presented the most contrast among plant attributes between the two states, and these are key traits predicting plant strategies, community assembly, and plant survival in fire-prone landscapes (Westoby et al. 2002, Curran et al. 2008, Craine 2009, Hoffmann et al. 2009, Brando et al. 2012, Lawes et al. 2012). The strong association between these traits and communities with different fire regimes provides additional support for the idea that fire-plant feedback processes regulate the dynamics of savanna and forest biomes, maintaining them as two different states with contrasting function, diversity, and assembly processes in tropical landscapes.

\section{ACKNOWLEDGMENTS}

We are grateful to Fundação de Amparo à Pesquisa do Estado de São Paulo (FAPESP; process: 2010/01835-0), Coordenação de Aperfeiçoamento de Pessoal de Nível Superior (CAPES; process: 1019-11-2), Conselho Nacional de Desenvolvimento Científico e Tecnológico (CNPq), and the Spanish Government (VIRRA and TREVOL projects, CGL200912048/BOS, CGL2012-39 938-C02-01) for financial support and the scholarships granted to the authors; to Instituto Brasileiro do Meio Ambiente e dos Recursos Naturais Renováveis (IBAMA), for research permission; to Emas National Park staff for logistical assistance; to G. D. Ávila, M. V. Cianciaruso, N. Escobar, A. Favari, V. Kadry, P. P. Loiola, R. Parmigiani, L. N. M. Ribeiro, N. Rosatti, G. Sartori, D. M. Silva, I. A. Silva, and E. L. Silva, Jr., for valuable help in the field sampling; to B. A. Severian for tree climbing; to $\mathrm{H}$. França for providing fire history data; and to M. V. Cianciaruso, M. Imatomi, J. A. Lombardi, V. Mantovani, I. A. Silva, M. Sobral, and J. Y. Tamashiro, for helping with species identification. The authors have no conflict of interest to declare.

\section{Literature Cited}

Archibald, S., and W. J. Bond. 2003. Growing tall vs growing wide: tree architecture and allometry of Acacia karoo in forest, savanna, and arid environments. Oikos 102:3-14.

Archibald, S., D. P. Roy, B. W. VanWilgen, and R. J. Scholes. 2009. What limits fire? An examination of drivers of burnt area in Southern Africa. Global Change Biology 15:613-630.

Batalha, M. A., W. Mantovani, and H. N. de Mesquita, Júnior. 2001. Vegetation structure in Cerrado physiognomies in South-Eastern Brazil. Brazilian Journal of Biology 61:475483.

Bond, W. J. 2008. What limits trees in $\mathrm{C}_{4}$ grasslands and savannas? Annual Review of Ecology, Evolution, and Systematics 39:641-659.

Bond, W. J. 2010. Do nutrient poor soils inhibit development of forest? A nutrient stock analysis. Plant and Soil 334:47-60.

Bond, W. J., and J. E. Keeley. 2005. Fire as a global 'herbivore': the ecology and evolution of flammable ecosystems. Trends in Ecology and Evolution 20:387-395. 
Bond, W. J., F. I. Woodward, and J. F. Midgley. 2005. The global distribution of ecosystems in a world without fire. New Phytologist 165:525-538.

Brando, P. M., D. C. Nepstad, J. K. Balch, B. Bolker, M. C. Christman, M. Coe, and F. E. Putz. 2012. Fire-induced tree mortality in a Neotropical forest: the roles of bark thickness, tree size, woody density and fire behavior. Global Change Biology 18:630-641.

Catry, F. X., F. Moreira, J. G. Pausas, P. M. Fernandes, F. Rego, E. Cardillo, and T. Curt. 2012. Cork oak vulnerability to fire: the role of bark harvesting, tree characteristics and abiotic factors. PLoS One 7:e39810.

Craine, J. M. 2009. Resource strategies of wild plants. Princeton University Press, Princeton, New Jersey, USA.

Curran, T. J., L. N. Gersbach, W. Edwards, and A. K. Krockenberger. 2008. Wood density predicts plant damage and vegetative recovery rates caused by cyclone disturbance in tropical rainforest tree species of North Queensland, Australia. Austral Ecology 33:442-450.

Dantas, V. L., J. G. Pausas, M. A. Batalha, P. P. Loiola, and M. V. Cianciaruso. 2013. The role of fire in structuring trait variability in Neotropical savannas. Oecologia 171:487-494.

Delitti, W. B. C., M. Meguro, and J. G. Pausas. 2006. Biomass and mineralmass estimates in a "Cerrado" ecosystem. Revista Brasileira de Botânica 29:531-540.

Enquist, B. J., G. B. West, E. L. Charnov, and J. H. Brown. 1999. Allometric scaling of production and life-history variation in vascular plants. Nature 401:907-911.

Gambiza, J., W. Bond, P. G. H. Frost, and S. Higgins. 2000. A simulation model of miombo woodland dynamics under different management regimes. Ecological Economics 33: 353-368.

Glitzenstein, J. S., W. J. Platt, and D. R. Streng. 1995. Effects of fire regime and habitat on tree dynamics in north Florida longleaf pine savannas. Ecological Monographs 65:441-476.

Goodland, R., and R. Pollard. 1973. The Brazilian Cerrado vegetation: a fertility gradient. Journal of Ecology 61:219 224.

Graham, C. H., and P. V. A. Fine. 2008. Phylogenetic beta diversity: linking ecological and evolutionary processes across space in time. Ecology Letters 11:1265-1277.

Hansen, B. E. 1997. Approximate asymptotic $P$ values for structural change tests. Journal of Business and Economic Statistics 15:60-67.

Haridasan, M. 1992. Observations on soils, foliar nutrients concentrations and floristic composition of Cerrado sensu stricto and cerradão communities in central Brazil. Pages 171-184 in J. Proctor, J.A. Ratter, and. P. A. Furley, editors. Nature and dynamics of forest-savanna boundaries. Chapman and Hall, London, UK.

Hennenberg, K. J., F. Fischer, K. Kouadio, D. Goetze, B. Orthmann, K. E. Linsenmair, F. Jeltsch, and S. Porembski. 2006. Phytomass and fire occurrence along forest-savanna transects in the Comoé National Park, Ivory Coast. Journal of Tropical Ecology 22:303-311.

Higgins, S. I., et al. 2007. Effects of four decades of fire manipulation on woody vegetation structure in savanna. Ecology 88:1119-1125.

Hirota, M., M. Holmgren, E. H. Van Nes, and M. Scheffer. 2011. Global resilience of tropical forest and savanna to critical transitions. Science 334:232-235.

Hoffmann, W. A., R. A. Dasme, M. Haridasan, M. T. Carvalho, E. L. Geiger, M. A. B. Pereira, S. G. Gotsch, and A. C. Franco. 2009. Tree topkill, not mortality, governs the dynamics of savanna-forest boundaries under frequent fire in central Brazil. Ecology 90:1326-1337.

Hoffmann, W. A., and A. C. Franco. 2003. Comparative growth analysis of tropical forest and savanna woody plants using phylogenetically independent contrasts. Journal of Ecology 91:475-484
Hoffmann, W. A., E. L. Geiger, S. G. Gotsch, D. R. Rossatto, L. C. R. Silva, O. L. Lau, M. Haridasan, and A. C. Franco. 2012a. Ecological thresholds at the savanna-forest boundary: how plant traits, resources and fire govern the distribution of tropical biomes. Ecology Letters 5:759-768.

Hoffmann, W. A., S. Y. Jaconis, K. L. Mckinley, E. L. Geiger, S. G. Gotsch, and A. C. Franco. 2012b. Fuel or microclimate? Understanding the drivers of fire feedbacks at savanna-forest boundaries. Austral Ecology 37:634-643.

Hoffmann, W. A., E. R. Silva, Jr., G. C. Machado, S. J. Bucci, F. G. Scholz, G. Goldstein, and F. C. Meinzen. 2005. Seasonal leaf dynamics across a tree density gradient in a Brazilian savanna. Oecologia 145:307-316.

Jung, V., C. Violle, C. Mondy, L. Hoffmann, and S. Muller. 2010. Intraspecific variability and trait-based community assembly. Journal of Ecology 98:1134-1140.

Keeley, J. E., W. J. Bond, R. A. Bradstock, J. G. Pausas, and P. W. Rundel. 2012. Fire in Mediterranean ecosystems: ecology, evolution and management. Cambridge University Press, Cambridge, UK.

Köppen, W. 1931. Grundriss der Klimakunde. Gruyter, Berlin, Germany.

Lawes, M. J., J. J. Midgley, and P. J. Clarke. 2012. Costs and benefits of relative bark thickness in relation to fire damage: a savanna/forest contrast. Journal of Ecology.

Lehmann, C. E. R., S. A. Archibald, W. A. Hoffmann, and W. J. Bond. 2011. Deciphering the distribution of the savanna biome. New Phytologist 191:197-209.

Markesteijn, L., L. Poorter, F. Bongers, H. Paz, and L. Sack. 2011. Hydraulics and life history of tropical dry forest tree species: coordination of species' drought and shade tolerance. New Phytologist 191:480-495.

Murphy, B. T., and D. M. J. S. Bowman. 2012. What controls the distribution of tropical forest and savanna? Ecology Letters 15:748-758.

Oliveira-Filho, A. T., and J. A. Ratter. 2002. Vegetation physiognomies and woody flora of the Cerrado biome. Pages 91-120 in P. S. Oliveira and R. J. Marquis, editors. The Cerrados of Brazil. Columbia University Press, New York, New York, USA.

Pausas, J. G. 1997. Resprouting of Quercus suber in NE Spain after fire. Journal of Vegetation Science 8:703-706.

Peterson, D. W., and P. B. Reich. 2001. Prescribed fire in oak savanna: fire frequency effects on stand structure and dynamics. Ecological Applications 11:914-927.

Pivello, V. R., and L. M. Coutinho. 1992. Transfer of macronutrients to the atmosphere during experimental burnings in an open Cerrado (Brazilian savanna). Journal of Tropical Ecology 8:487-497.

Pueyo, S., P. M. L. A. Graça, R. I. Barbosa, R. Cots, E. Cardona, and P. M. Fearnside. 2010. Testing for criticality in ecosystem dynamics: the case of Amazonian rainforest and savanna fire. Ecology Letters 13:793-802.

R Development Core Team. 2011. R: A language and environment for statistical computing. R Foundation for Statistical Computing, Vienna, Austria. http://www. r-project.org

Ramos-Neto, M. B., and V. R. Pivello. 2000. Lightning fires in a Brazilian savanna national park: rethinking management strategies. Environmental Management 26:675-684.

Ratnam, J., W. J. Bond, R. J. Fensham, W. A. Hoffmann, S. Archibald, C. E. R. Lehmann, M. T. Anderson, S. I. Higgins, and M. Sankaran. 2011. When is a 'forest' a savanna, and why does it matter? Global Ecology and Biogeography 20: 653-660.

Rossatto, D. R., W. A. Hoffmann, and A. C. Franco. 2009. Differences in growth patterns between co-occurring forest and savanna trees affect the forest-savanna boundary. Functional Ecology 23:689-698. 
Salis, S. M., M. A. Assis, P. P. Mattos, and A. C. S. Pião. 2006. Estimating the aboveground biomass and wood volume of savanna woodlands in Brazil's Pantanal wetlands based on allometric correlations. Forest Ecology and Management 228:61-68.

Simon, M. F., R. Gretherc, L. P. Queiroz, C. Skemae, R. T. Penningtone, and C. E. Hughes. 2009. Recent assembly of the Cerrado, a Neotropical plant diversity hotspot, by in situ evolution of adaptations to fire. Proceedings of the National Academy of Sciences USA 48:20 359-20 364.

Staver, A. C., S. Archbald, and A. S. Levin. 2011. The global extent and determinants of savanna and forest as alternative biome states. Science 334:230-232.

Staver, A. C., and A. S. Levin. 2012. Integrating theoretical climate and fire effects on savanna and forest systems. American Naturalist 180:211-224.
Toms, J. D., and M. S. Lesperance. 2003. Piecewise regression: a tool for identifying ecological thresholds. Ecology 84:20342041.

Trauernicht, C., B. P. Murphy, T. E. Portner, and D. M. J. S. Bowman. 2012. Tree cover-fire interactions promote the persistence of a fire-sensitive conifer in a highly flammable savanna. Journal of Ecology 100:958-968.

Verdú, M., and J. G. Pausas. 2007. Fire drives phylogenetic clustering in Mediterranean Basin woody plant communities. Journal of Ecology 95:1316-1323.

Westoby, M., D. S. Falster, A. T. Moles, P. A. Vesk, and I. J. Wright. 2002. Plant ecological strategies: some leading dimensions of variation between species. Annual Review of Ecology, Evolution, and Systematics 33:125-159.

Woodward, F. I., M. R. Lomas, and C. K. Kelly. 2004. Global climate and the distribution of plant biomes. Philosophical Transactions of the Royal Society B 359:1465-1476.

\section{Supplemental Material}

\section{Appendix A}

Examples of the variability in community and individual plant attributes in Emas National Park, central Brazil (Ecological Archives E094-225-A1).

\section{Appendix B}

Detailed description of field and laboratory methods (Ecological Archives E094-225-A2).

\section{Appendix C}

Relationship between the community closure index (CCI) and basal area per hectare (Ecological Archives E094-225-A3).

\section{Appendix D}

Soil variables, leaf toughness, and diversity indices along the community closure index gradient (CCI) and their breakpoints (Ecological Archives E094-225-A4).

\section{Appendix E}

Distribution of basal area and mean height at each side of the threshold (Ecological Archives E094-225-A5). 